Vol 11, Issue 11, 2018

\title{
STREPTOZOTOCIN-INDUCED OXIDATIVE STRESS IN DIABETIC RATS - A DEFENSIVE EFFECT OF PSYDRAX DICOCCOS
}

\author{
RAVI KUMAR V ${ }^{1 *}$, SAILAJA RAO P ${ }^{2}$ \\ ${ }^{1}$ Department of Pharmacology, M.N.R. College of Pharmacy, Sangareddy, Telangana, India. ${ }^{2}$ Department of Pharmacology, \\ Sri Venkateshwara College of Pharmacy, Hyderabad, Telangana, India. Email: sailajarao476@gmail.com
}

Received: 20 June 2018, Revised and Accepted: 27 July 2018

\section{ABSTRACT}

Objective: The present study was aimed to evaluate the antihyperglycemic activity and in vivo antioxidant effect of methanolic extract of whole plant of Psydrax dicoccos (MEPD) belonging to the family Rubiaceae.

Methods: MEPD was prepared by Soxhlet extraction. Wistar rats weighing (180-200 g) were divided into six groups (n=6), with three doses of $100 \mathrm{mg} / \mathrm{kg}, 200 \mathrm{mg} / \mathrm{kg}$, and $400 \mathrm{mg} / \mathrm{kg}$ of extract. Metformin was used as a standard drug. Diabetes was induced by streptozotocin (STZ) $\left(40-50 \mathrm{mg} / \mathrm{kg}\right.$, i.p) in control group. The animals were treated with different doses of extracts for 21 days, and on the $22^{\text {nd }}$ day, the blood glucose levels along with antioxidant enzymes such as superoxide dismutase (SOD), catalase (CAT), and lipid peroxidase (LPO) were determined.

Results: The phytochemical screening of the extract showed the presence of carbohydrates, phenolics, flavonoids, glycosides, and tannins. The methanolic extract of MEPD at the dose of $200 \mathrm{mg} / \mathrm{kg}$ body weight showed a significant reduction in blood glucose levels (**p<0.001) with the value of $151.2 \mathrm{mg} / \mathrm{dl}$ on the $22^{\text {nd }}$ day at $8 \mathrm{~h}$. A promising antioxidant effect was also evident from the determination of antioxidant enzymes such as SOD, CAT, and LPO.

Conclusion: The P. dicoccos extract revealed a potential effect of antihyperglycemic activity and combating nature on oxidative stress induced by STZ.

Keywords: Psydrax dicoccos, Streptozotocin, Blood glucose, Catalase, Lipid peroxidase.

(C) 2018 The Authors. Published by Innovare Academic Sciences Pvt Ltd. This is an open access article under the CC BY license (http://creativecommons. org/licenses/by/4. 0/) DOI: http://dx.doi.org/10.22159/ajpcr.2018.v11i11.28019

\section{INTRODUCTION}

Diabetes mellitus is a metabolic disorder characterized by hyperglycemia with hampered metabolism of vital biological components such as carbohydrate, protein, and lipids. The effects are mainly due to the defective insulin secretion, loss of insulin receptors, or both [1]. Earlier century in India, two physicians "Charaka and Susruta" reported the disease. However, in the $18^{\text {th }}-19^{\text {th }}$ century, hyperglycemia is less visualized clinically, identified by uncontrolled glycosuria, and usually diagnosed in later stage of life; currently, it is recognized as type 2 diabetes mellitus. Persistent higher blood glucose levels generate free radicals that may lead to the development of oxidative stress in distinct parts of the body which further culminate to various complications such as cardiovascular, neurodegenerative, chronic kidney failure, ocular damage, and vascular diseases [2]. Free radicals are highly unstable reactive oxygen species (ROS) produced regularly in various normal biological reactions in the human system. Whenever these free radicals are produced, their effects are monitored by defense system of the body which includes antioxidant enzymes such as superoxide dismutase (SOD), catalase (CAT), glutathione peroxidase, glutathione reductase (GR), and lipid peroxidase (LPO) [3]. This "oxidative shielding" acts as a protective mechanism to counter the attack of toxic pathogens or noxious chemicals or to destruct the cell by apoptosis and thus preventing its advancement to neighboring cells [4]. The term "oxidative stress" is biological state in which ROS and RNS level attain a maximum peak, either by excess production or insufficient removal. Since ROS and RNS have been a highly reactive molecule, it will cause some alteration to vital biological proteins, carbohydrates, DNA, lipids, and other molecules, further prelude to physiological dysfunction of cells and pathologic condition such as diabetes, heart diseases, and cancer [5].

Antioxidants are the compounds that can prevent (or) inhibit oxidation chain reaction process in living cells [6]. The use of synthetic agents is frequently associated with several undesirable side effects and fails to correct the fundamental biochemical lesion and diabetic complications. From the researcher's point of view, investigation on medicinal plants has gained importance because of their natural origin and fewer side effects [6]. New therapies are needed which control the hyperglycemic condition and prevent long-term complications. Although there are drugs which were reported to control blood glucose levels of diabetic subjects/animal models, these failed to control complications of diabetes because of side/toxic effects such as hepatotoxicity or cardiac failure. Therefore, authentic evaluation is needed for herbal drug with an expectation of product efficacy, safety, and therapeutic risk/benefit. Hence, the current research aims to scientifically investigate the traditionally used medicinal plants in the treatment of diabetes mellitus, their insulin secretagogue action, and potent antioxidant effect.

Psydrax dicoccos Gaertn. (Syn. Canthium dicoccum [Gaertn.]) belongs to the family Rubiaceae and the plant is found in all parts of tropical regions of India. It is an unarmed shrub, grows up to $3 \mathrm{~m}$ tall. All the plant parts have been recognized to have medicinal properties such as antiinflammatory, digestive, anti-necrotic, hepatoprotective, neuroprotective, and antioxidant property. It is also used for fever and also applied as plasters; decoction of the root is used in diarrhea. Bark powder with sesame oil is used in rheumatic pains. Used in inflammation, during night boiled leaf extract is taken for 2 months [7]. A number of flavonoids have been shown to suppress carcinogenesis in various animal models. Flavonoids are also responsible as effective scavengers, which participate in antioxidant mechanism. The present study was taken up to evaluate the antihyperglycemic property and antioxidant effect of whole plant extract (methanolic) of P. dicoccos streptozotocin (STZ)-induced diabetic rats [8].

\section{METHODS}

Collection of plant material and preparation of extract [9] The whole plant $P$. dicoccos was procured from Tirumala Hills, Tirupati, and was authenticated by Dr. Madhava Chetty, Botanist, Sri 
Venkateshwara University, Tirupati, Andhra Pradesh. The plant material was powdered and extracted with methanol in a Soxhlet apparatus at a temperature of $60^{\circ} \mathrm{C}$ for $12 \mathrm{~h}$. The resultant extract was filtered, and the filtered extract was then concentrated to dryness in a rotary evaporator under reduced pressure and stored in a desiccator.

\section{Preparation of extract}

Suspension of methanolic extract of Psydrax dicoccos (MEPD) was prepared in $0.1 \%$ dimethyl sulfoxide as a suspending agent. The extract was administered at three doses of 100,200 , and $400 \mathrm{mg} / \mathrm{kg}$, respectively.

\section{Preliminary phytochemical analysis}

The MEPD was screened for the presence of various phytoconstituents such as alkaloids, carbohydrates, phenolics, flavonoids, glycosides, and tannins.

\section{Acute toxicity studies [10]}

Albino rats weighing 150-250 g were selected by random sampling technique and used for the study. Acute oral toxicity was performed as per OECD-423 guidelines (acute class method). The animals were fasted overnight, provided only water after which extract was administered to the groups orally at the dose level of $5 \mathrm{mg} / \mathrm{kg}$ body weight by gastric intubation, and the groups were observed for 14 days. If mortality was observed in two or three animals, among six animals, then the dose administered was assigned as a toxic dose. If mortality was observed in one animal, then the same dose was repeated again to confirm the toxic dose.

If mortality was not observed, the procedure was repeated for further higher doses such as 50, 300, and $2000 \mathrm{mg} / \mathrm{kg}$ body weight. The animals were observed for toxic symptoms such as behavioral changes, locomotion, convulsions, and mortality for $72 \mathrm{~h}$. It was observed that the test extract was not mortal even at a dose of $2000 \mathrm{mg} / \mathrm{kg}$ body weight. Hence, $250 \mathrm{mg} / \mathrm{kg}$ and $500 \mathrm{mg} / \mathrm{kg}$ doses were selected for the study.

\section{Animals}

Adult male rats of Wistar albino strain weighing between 150 and $200 \mathrm{~g}$ were obtained from our college animal house. They were kept in polypropylene cages with not more than five animals per cage and allowed to get acclimatized to a standard laboratory diet. The animals were adapted to laboratory condition before the experiments at constant room temperature of $22 \pm 1^{\circ} \mathrm{C}$ temperature with $12 \mathrm{~h}$ light and dark cycle. Feed (standard pellets) and drinking water were provided ad libitum. The experimental protocol was duly approved by the Institutional Animal Ethical Committee (IAEC) of Committee for the Purpose of Control and Supervision of Experimentation on animals through its reference no: IAEC/SVCP/2016/007, Dated: 27/2/16.

\section{Induction of experimental diabetes [11]}

Induction of experimental diabetes: Diabetes was induced by a single intraperitoneal injection of a freshly prepared STZ solution (Sisco Research Laboratories Pvt., Ltd., Mumbai-93, India) (Batch No: T-835796) (Dose: $30-50 \mathrm{mg} / \mathrm{kg}$ ) in citrate buffer $0.1 \mathrm{M}, \mathrm{pH} 4.5$ to overnight fasted rats. Diabetes was identified by polydipsia, polyuria, and by measuring blood glucose levels $48 \mathrm{~h}$ after injection of STZ.
Animals which did not develop more than $250 \mathrm{mg} / 100 \mathrm{ml}$ of blood glucose levels were rejected.

\section{Experimental design}

The experiment was carried out in six groups of six rats each:

Group I: Normal control rats received saline

Group II: Diabetic control (DC)

Group III: DC + Metformin $(50 \mathrm{mg} / \mathrm{kg})$

Group IV: DC + MEPD (100 mg/kg)

Group V: DC + MEPD (200 mg/kg)

Group VI: DC + MEPD (400 mg/kg).

Diabetes was induced by administering STZ and the animals of Groups IV, V, and VI were treated with the extracts at specified doses for 21 days. On the $22^{\text {nd }}$ day, the blood was withdrawn from retro-orbital plexus and centrifuged serum glucose levels were estimated on at $0 \mathrm{~h}$, 1 h, 2 h, 4 h, 6 h, and 8 h, respectively, by glucose oxidase method, and absorbance was measured at $505 \mathrm{~nm}$ by UV spectrophotometer [12]. At the end of the experimental period, the animals were deprived of food overnight and sacrificed by decapitation. The liver was removed and homogenized for in vivo antioxidant activity.

\section{In vivo antioxidant activities}

Lipid peroxidation is based on the reaction of malondialdehyde (MDA) one of the products of lipid peroxidation with thiobarbituric acid to form thiobarbituric acid reactive substances, which has a pink color with absorption maxima at $540 \mathrm{~nm}$ [13]. CAT activity was determined according to the method of Aebi [14]. SOD activity was determined calorimetrically by the method of Kono [15]. Ascorbic acid was taken as a standard agent.

\section{Statistical analysis}

The results are expressed as mean \pm standard deviation. Comparison between the groups was made by analysis of variance, followed by Dunnett's test as per suitability. $\mathrm{p}<0.001$ was considered statistically significant. Statistical calculations were done using GraphPad Prism version 6.0 .

\section{RESULTS AND DISCUSSION}

From ancient times, diabetic patients have used medicinal plants to maintain blood glucose level. In this regard, the present study was extended to show the influence of extracts on the blood glucose levels and oxidative stress.

The preliminary phytochemical analysis showed that MEPD was found to possess various phytoconstituents such as carbohydrates, phenolics, flavonoids, glycosides, and tannins, whereas alkaloids were absent.

MEPD (200 mg/kg) and metformin (50 mg/kg) showed significant $(\mathrm{p}<0.001)$ fall in blood glucose levels at $1 \mathrm{~h}, 2 \mathrm{~h}, 4 \mathrm{~h} 6 \mathrm{~h}$, and $8 \mathrm{~h}$, respectively, when compared with DC group (Table 1 ).

Table 2 shows the effect of administration of MEPD on MDA, CAT, and SOD in liver tissue of different groups of rats. There was a significant $(\mathrm{p}<0.001)$ elevation in tissue MDA in diabetic rats as compared to normal

Table 1: Effect of MEPD on blood glucose levels in diabetic rats

\begin{tabular}{|c|c|c|c|c|c|c|}
\hline \multirow[t]{2}{*}{ Treatment and dose } & \multicolumn{6}{|c|}{ Serum glucose levels (mg/dl) } \\
\hline & $\mathbf{0 ~ h}$ & $1 \mathrm{~h}$ & $2 \mathrm{~h}$ & $4 h$ & $6 \mathrm{~h}$ & $8 \mathrm{~h}$ \\
\hline Normal & $94.4 \pm 3.8$ & $86.5 \pm 3.21$ & $91.3 \pm 2.03$ & $82.9 \pm 0.85$ & $85 \pm 0.36$ & $82.6 \pm 0.95$ \\
\hline DC+Metformin (50 mg/kg) & $280 \pm 7.3$ & $262 \pm 3.45$ & $152.3 \pm 4.08^{* *}$ & $138.3 \pm 1.82 * *$ & $137 \pm 0.51^{* *}$ & $129.1 \pm 0.98^{* *}$ \\
\hline $\mathrm{DC}+\mathrm{MEPD}(100 \mathrm{mg} / \mathrm{kg})$ & $270 \pm 9.01$ & $255.6 \pm 3.08$ & $250.1 \pm 2.2$ & $261.2 \pm 2.62$ & $251.6 \pm 1.22$ & $259 \pm 2.62$ \\
\hline DC+MEPD (200 mg/kg) & $275.6 \pm 3.48$ & $250.6 \pm 6.67^{*}$ & $185.5 \pm 3.66^{* *}$ & $165.87 \pm 3.01^{* *}$ & $160.02 \pm 2.1^{* *}$ & $150.6 \pm 1.27^{* *}$ \\
\hline DC+MEPD (400 mg/kg) & $270.6 \pm 3.66$ & $255.8 \pm 3.66^{*}$ & $250.78 \pm 2.67$ & $245.07 \pm 1.68$ & $240.8 \pm 1.12$ & $240.67 \pm 1.67$ \\
\hline
\end{tabular}

The data are expressed in mean \pm S.E.M, $\mathrm{n}=6$ in each group, ${ }^{* *} \mathrm{p}<0.001$, significant, compared to DC. MEPD: Methanolic extract of Psydrax dicoccos, DC: Diabetic control,

SEM: Standard error of the mean 
Table 2: Effect of MEPD on antioxidant enzymes in diabetic rats

\begin{tabular}{|c|c|c|c|c|}
\hline Groups & Treatment and dose (mg/kg) & SOD & CAT & MDA \\
\hline I & Control & $68.7 \pm 0.98$ & $22.05 \pm 0.56^{* *}$ & $15.57 \pm 0.48^{* *}$ \\
\hline II & DC & $17.87 \pm 0.89 * *$ & $8.19 \pm 1.19^{* *}$ & $56.33 \pm 1.72^{* *}$ \\
\hline III & DC+Metformin $(50 \mathrm{mg} / \mathrm{kg})+$ Ascorbic acid $(100 \mathrm{mg} / \mathrm{kg})$ & $48 \pm 0.77^{* *}$ & $18.01 \pm 0.66^{* *}$ & $18.06 \pm 1.08^{* *}$ \\
\hline IV & DC+MEPD (100 mg/kg) & $18.67 \pm 2.98^{\mathrm{NS}}$ & $9.98 \pm 2.16^{\mathrm{NS}}$ & $56.66 \pm 2.06^{\mathrm{NS}}$ \\
\hline V & DC+MEPD (200 mg/kg) & $38.67 \pm 3.01^{* *}$ & $42.06 \pm 2.26^{* *}$ & $18.06 \pm 1.89 * *$ \\
\hline VI & DC+MEPD (400 mg/kg) & $19.67 \pm 0.6^{\mathrm{NS}}$ & $9.12 \pm 1.16^{\mathrm{NS}}$ & $52.66 \pm 1.16^{\mathrm{NS}}$ \\
\hline
\end{tabular}

The data are expressed in mean \pm S.E.M; $\mathrm{n}=6$ in each group; ${ }^{* *} \mathrm{p}<0.001$, significant, compared to DC. MEPD: Methanolic extract of $p s y d r a x$ dicoccos, DC: Diabetic control, SEM: Standard error of the mean. SOD: Superoxide dismutase, CAT: Catalase, MDA: Malondialdehyde. NS: Non-significant

rats. Treatment with MEPD at a dose of $200 \mathrm{mg} / \mathrm{kg}$ for 21 days resulted in significant $(\mathrm{p}<0.001)$ decrease in liver tissue MDA. CAT and SOD in DC rats were significantly $(\mathrm{p}<0.001)$ depleted in liver tissue when compared to normal rats. MEPD treatment at a dose of $200 \mathrm{mg} / \mathrm{kg}$ significantly $(\mathrm{p}<0.001)$ restored CAT and SOD levels as compared to DC rats.

In the present study, we examined the effects of MEPD on oxidative stress and $\beta$-cell damage in STZ-induced diabetic rats. Diabetics and experimental models exhibit high oxidative stress due to persistent and chronic hyperglycemia, which causes depletion of antioxidative defense system and promote de novo generation of free radicals. STZ is most commonly used to induce diabetes in rats. This causes the death of pancreatic $\beta$-cell by alkylation of DNA resulting in reduced synthesis and release of insulin. This results in fragmentation of DNA by means of production of ROS. STZ causes massive destruction of $\beta$-cells of the islets of Langerhans resulting in the insulin synthesis and secretion [16]. The toxic effect of STZ is not restricted to abolishment of pancreatic $\beta$-cells but also causes oxidative stress. Continuous exposure of the system to free radicals results in decreased activities of SOD and CAT.

The results presented in Table 1 indicated that $P$. dicoccos plant extract produced antihyperglycemic activity in a dose-dependent manner. Further, at a dose of $200 \mathrm{mg} / \mathrm{kg}$, the extract produced significant antihyperglycemic activity when compared with the reference compound metformin. Here, the glucose lowering activity of $P$. dicoccos may be attributed to both pancreatic (enhancement of insulin secretion) and extrapancreatic (peripheral utilization of glucose) mechanisms.

The present data indicated that STZ-induced diabetes disrupts the actions of antioxidant enzymes. The decreased activities of these enzymes may be due to the production of ROS such as superoxide $\left(\mathrm{O}_{2}{ }^{\circ}\right)$, hydrogen peroxide $\left(\mathrm{H}_{2} \mathrm{O}_{2}\right)$, and hydroxyl radical $(\cdot \mathrm{OH})$ that reduced the activity of these enzymes [11]. In the present study, MEPD potentiated the in vivo antioxidant activities. Elevation of LPO is attributed to the enhanced production of the ROS. In the present study, we observed an MDA formation, the index of lipid peroxidation was significantly increased in the liver of STZ-treated animals. MEPD supplementation potentially reduced MDA level, suggesting that MEPD might have antioxidant principles to produce such a response. CAT and SOD protect the cellular system against the toxic effects of lipid peroxidation. A marked depletion in both the enzymes of a liver was observed in DC rats (Table 2). Furthermore, MEPD treatment showed a significant restoration in CAT and SOD of diabetic rats.

In the present study, findings showed positive effect of $P$. dicoccos on rats with STZ-induced disturbances in the glucose level and the antioxidant status. Thus, MEPD is beneficial in the control of diabetes and oxidative stress by activation of enzymatic antioxidants.

\section{CONCLUSION}

The result of the present study indicates that $P$. dicoccos may have active principle(s) which are responsible for the potent antidiabetic activity. However, more efforts are still required for the isolation, characterization, and biological evaluation of the active principle(s) of P. dicoccos extract.

\section{ACKNOWLEDGMENT}

The authors are thankful to the Professor and Principal of M.N.R. College of Pharmacy, Dr. V. Alagarswamy, for his constant support and encouragement to carry out this project.

\section{AUTHORS' CONTRIBUTION}

Both the authors have equal contribution with regard to the work and write up.

\section{CONFLICTS OF INTEREST}

The authors have no conflicts of interest absolutely with anyone.

\section{REFERENCES}

1. World Health Organization. Global Report on Diabetes. Diabetes Mellitus - Epidemiology, Prevention and Control, Diabetes and Gestational. Geneva: World Health Organization; 2016.

2. Rao PS, Mohan Gk. In vitro alpha amylase inhibition and in vivo anti-oxidant potential of Momordica dioica in streptozotocin induced diabetic rats. Saudi J Bio Sci 2017:24:1262-7.

3. Jyothi SG, Chavan SC, Somashekaraiah BV. In vitro and in vivo antioxidant and anti-diabetic efficacy of Cassia auriculata L. Flowers. Global J Pharmacol 2012;6:33-40.

4. Naviaux RK. Oxidative shielding or oxidative stress? J Pharmacol Exp Ther 2012;342:608-18

5. Rochette L, Zeller M, Cottin Y, Vergely C. Diabetes, oxidative stress and therapeutic strategies. Biochim Biophys Acta 2014;1840:2709-29.

6. Urmila UT, Supada RR. In vitro anti-oxidant and in vivo antiinflammatory activity of the aerial part of Blumea eriantha DC. Int J Pharm Phal Sci 2018;10:75-9.

7. Rajeswari NR, Lakshmi SR, Muthuchelian K. GC-MS analysis of bioactive components from the ethanolic leaf extract of Canthium dicoccum (Gaertn.). Teys and Binn. J Chem Pharm Res 2011;3:792-8.

8. Umaiyambigai D, Kumar KS, Raj GA. Free radical scavenging activity, phenol and flavanoid, contents of various solvent extracts from the Psydrax dicoccos (Gaertn.). Int J Appl Res 2017;3:394-402.

9. Umaiyambigai D, Kumar KS, Raj GA. Phytochemical profile and anti-fungal activity of leaves of methanolic extract from the Psydrax dicoccos (Gaertn.) Rubiaceae family. Int J Pharm Phytochem Ethnomed 2017:7:53-61

10. OECD Guidelines for Testing of Chemicals. Acute Oral Toxicity-Acute Toxic Class Method 423

11. Latha M, Pari L, Ramkumar KM, Rajaguru P, Suresh T, Dhanabal T, et al. Antidiabetic effects of scoparic acid D isolated from Scoparia dulcus in rats with streptozotocin induced diabetic rats. Nat Prod Res 2009;23:1528-40.

12. Sabu MC, Subburaju T. Effect of Cassia auriculata linn. On serum glucose level, glucose utilization by isolated rat hemidiaphragm. J Ethnopharmacol 2002;80:203-6.

13. Ohkawa H, Ohishi N, Yagi K. Assay for lipid peroxides in animal tissues by thiobarbituric acid reaction. Anal Biochem 1979;95:351-8.

14. Aebi H. Catalase. In: Hu B, editor. Methods in Enzymatic Analysis. New York: Academic press; 1983. p. 276-86

15. Kono Y. Generation of superoxide radical during autoxidation of hydroxylamine and an assay for superoxide dismutase. Arch Biochem Biophys 1978;186:189-95.

16. Bhardwaj A, Modi KP. Anti-diabetic and anti-hyperlipidaemic activity of Nelumbo nucifera goertn ethanol seed extract in streptozotocin induced diabetic rats. Int J Pharm Pharm Sci 2017;9:197-204. 